Phar macoki net i cs and phar macodynamics of i nsul in aspart in pat i ent s wi th Type 2 di abet es: Assessment usi ng a meal tol er ance test under cli ni cal condi ti ons

\begin{tabular}{|l|l|}
\hline 著者 & $\begin{array}{l}\text { Ando H t oshi, Kur i ta Sei i chi ro, Shi mi zu Aki ko, } \\
\text { Kat o Ken- i chi ro, I shi kur a Kazuhi de, Taj i } \\
\text { Koumei, Uno Nasaf umi, Takeshi ta Yum e, M su } \\
\text { H r of um, Fuj i mur a Aki o, Kaneko Shui chi , } \\
\text { Takamur a Toshi nar i }\end{array}$ \\
\hline $\begin{array}{l}\text { j our nal or } \\
\text { publ i cat i on ti t l e }\end{array}$ & $\begin{array}{l}\text { Cl i ni cal and Exper i ment al Phar nacol ogy and } \\
\text { Physi ol ogy }\end{array}$ \\
\hline vol une & 39 \\
\hline nunber & 6 \\
\hline page r ange & $528-534$ \\
\hline year & $2012-06-01$ \\
\hline URL & ht t p: //hdl . handl e. net /2297/31973 \\
\hline
\end{tabular}




\title{
Pharmacokinetics and pharmacodynamics of insulin aspart in patients with type 2 diabetes: Assessment using a meal tolerance test under clinical conditions
}

\author{
Hitoshi Ando, ${ }^{* \dagger}$ Seiichiro Kurita, ${ }^{*}$ Akiko Shimizu, ${ }^{*}$ Ken-ichiro Kato, ${ }^{*}$ \\ Kazuhide Ishikura, ${ }^{*}$ Koumei Taji, ${ }^{*}$ Masafumi Uno, ${ }^{*}$ Yumie Takeshita, ${ }^{*}$ \\ Hirofumi Misu, ${ }^{*}$ Akio Fujimura, ${ }^{\dagger \dagger}$ Shuichi Kaneko* and Toshinari Takamura*
}

*Department of Disease Control and Homeostasis, Kanazawa University Graduate

School of Medical Science, Kanazawa, and Division of Clinical Pharmacology, Department of Pharmacology, School of Medicine, Jichi Medical University, Shimotsuke, Japan

Short title: Pharmacokinetics of insulin aspart

Correspondence to Hitoshi Ando, MD, PhD,

Division of Clinical Pharmacology, Department of Pharmacology, School of Medicine, Jichi Medical University, 3311-1 Yakushiji, Shimotsuke, Tochigi 329-0498, Japan.

Telephone number: +81-285-58-7388 Fax number: +81-285-44-7562

E-mail: h-ando@jichi.ac.jp 


\section{SUMMARY}

1. Few studies have evaluated the pharmacokinetics of rapid-acting insulin analogues in patients with type 2 diabetes, especially under clinical conditions. The aim of this study was to assess both the pharmacokinetics and pharmacodynamics of insulin aspart in type 2 diabetic patients who were being treated with the analogue alone.

2. Meal tolerance tests with and without self-injection of a customary dose of insulin aspart $(0.05-0.22 \mathrm{U} / \mathrm{kg})$ were conducted in 20 patients in a randomised crossover study.

3. The dose (per body weight) of insulin aspart was significantly correlated with both the maximum concentration $\left(r^{2}=0.59, P<0.01\right)$ and area under the concentration-time curve for insulin aspart $\left(r^{2}=0.53, P<0.01\right)$. However, the time to maximum concentration $\left(t_{\max }\right)$, which varied widely from $<60 \mathrm{~min}$ to $\geq 120 \mathrm{~min}$, was not associated with either dosage $\left(r^{2}=0.02, P=0.51\right)$ or body mass index $\left(r^{2}=0.02\right.$, $P=0.57)$. Injection of insulin aspart exacerbated delayed hyperinsulinaemia after meal loading, mainly in patients with $t_{\max }$ values $\geq 120 \mathrm{~min}$. With regard to pharmacodynamics, insulin aspart had favourable effects on postprandial hyperglycaemia, hyperglucagonaemia, and hyperlipidaemia.

4. The $t_{\max }$ for this insulin analogue differed greatly between individuals, and delayed hyperinsulinaemia was particularly exacerbated in patients with higher $t_{\max }$ values. Identification of the factors contributing to inter-individual variation in the absorption lag time is essential for improving its efficacy and safety.

Key words: insulin aspart, rapid-acting insulin analogues, delayed hyperinsulinaemia, 
glucagon, postprandial hyperlipidaemia 


\section{INTRODUCTION}

The elevation of postprandial plasma glucose levels, which occurs due to the loss of first-phase insulin secretion, decreased insulin sensitivity, and consequent defective suppression of hepatic glucose output after meals, begins prior to the onset of type 2 diabetes. ${ }^{1,2}$ Therefore, postprandial hyperglycaemia is common in patients with type 2 diabetes, even when overall glycaemic control, as assessed by measuring glycosylated haemoglobin levels, appears to be adequate. ${ }^{3}$ Because post-challenge hyperglycaemia is known to be an independent risk factor for cardiovascular disease and all-cause mortality, ${ }^{4,5}$ various agents that target postprandial plasma glucose, including rapid-acting insulin analogues, are now used clinically in the treatment of type 2 diabetes. Of note, mealtime dosing of a rapid-acting insulin analogue, without basal insulin or any other medications, improved both postprandial and early morning fasting plasma glucose levels in approximately one-half of 40 Japanese patients with type 2 diabetes. $^{6}$

Insulin aspart is a rapid-acting insulin analogue in which proline 28 in the B chain has been replaced by aspartic acid. $^{7}$ Several studies have investigated the pharmacokinetics of insulin aspart and have compared the results to those for regular insulin $^{7-14}$ or other rapid-acting insulin analogues. ${ }^{15-18}$ However, most of these studies were conducted in healthy subjects ${ }^{7-10,13,18}$ or patients with type 1 diabetes. ${ }^{12,16,17}$ In addition, studies in patients with type 2 diabetes used a dose of insulin aspart that was weight-adjusted, but not clinically appropriate for each patient. ${ }^{11,14,15}$ Recently, Gagnon-Auger et al. ${ }^{19}$ used a euglycaemic clamp to show that the pharmacokinetics of 
insulin lispro, another rapid-acting insulin analogue, differ between healthy subjects and patients with type 2 diabetes, and that the time to maximum concentration $\left(t_{\max }\right)$ is dose-dependently increased in diabetic patients. Therefore, the pharmacokinetics of insulin aspart should be assessed in patients with type 2 diabetes, especially under clinical conditions. To address the issue, we determined the pharmacokinetics of a customary dose of insulin aspart administered immediately before eating in type 2 diabetic patients receiving insulin aspart monotherapy. Another trial with a randomised crossover design was performed without insulin aspart. By comparing the concentration-time profiles of endogenous insulin, glucose, glucagon, triglycerides, and remnant-like particle (RLP)-cholesterol in these trials, we further evaluated the pharmacodynamics of insulin aspart in a clinical setting. 


\section{METHODS}

\section{Patients}

This study was conducted between February and June 2007. A total of 20 Japanese patients with type 2 diabetes were recruited from the outpatient clinic at Kanazawa University Hospital (Kanazawa, Japan) based on the following inclusion criteria: 1) treatment with insulin aspart monotherapy, i.e., dosing of pure insulin aspart at each mealtime without combined administration of any oral antidiabetic agent or other insulin preparation $^{6}$ for at least 3 months; 2) relatively good and stable glycaemic control, as defined by two consecutive haemoglobin $\mathrm{A}_{1 \mathrm{c}}$ measurements of $<7.4 \%$ and a difference between measurements of $<0.5 \%$; and 3) all chronic diseases other than type 2 diabetes, such as hypertension and dyslipidaemia, being stable. For insulin aspart monotherapy, the breakfast, lunch, and dinner doses of insulin aspart were adjusted in an attempt to achieve plasma glucose levels of 4.4-6.7 $\mathrm{mmol} / \mathrm{l}$ before lunch, dinner, and bedtime, respectively. Patients with anaemia, acute diseases, existing malignancy, or severe renal or hepatic dysfunction, as well as women of childbearing potential, were excluded. Five healthy, non-diabetic Japanese individuals were recruited as controls. The characteristics of the subjects are shown in Table 1. Eight patients with diabetes had been treated with one or more antihypertensive medications: angiotensin receptor blocker $(n=5)$, calcium channel blocker $(n=5)$, diuretic $(n=2)$, beta-blocker $(n=1)$, or angiotensin-converting enzyme inhibitor $(n=1)$. Six patients received continuous treatment with a lipid-lowering agent: $\operatorname{statin}(n=5)$ or fibrate $(n=1)$. 
This study was approved by the ethics committee of Kanazawa University (Kanazawa, Japan) and was conducted in accordance with the Declaration of Helsinki. All subjects provided written informed consent before participating in the study.

\section{Study design}

In the morning following an overnight fast, participants consumed a test meal developed by a working group of the Japan Diabetes Society $(460 \mathrm{kcal}$; protein, $18.0 \mathrm{~g}$; fat, 18.0 g; carbohydrate, 56.5 g; E460F18, Q. P. Corp., Tokyo, Japan), along with 100 $\mathrm{ml}$ of water, within $15 \mathrm{~min} .{ }^{20}$ The participants were asked to remain seated and blood samples were obtained immediately before and at 30,60, 120, and $180 \mathrm{~min}$ after ingestion of the test meal. In diabetic patients, tests with and without subcutaneous administration of insulin aspart (NovoRapid; Novo Nordisk Pharma Ltd., Tokyo) just before meal loading were conducted according to a randomised crossover schedule with an interval ranging from 7 to 56 days (mean, 20 days). Insulin aspart was administered in the abdomen at a customary dose for breakfast time (range, 3-12 U; mean, 7.0 U). The insulin injection site and technique were checked by at least one doctor. All participants completed the study, and the medications taken by the diabetic patients did not change throughout the study period.

\section{Assays}

Serum concentrations of total insulin (i.e., endogenous insulin plus exogenous insulin aspart) were measured using an E-test TOSOH II IRI immunoassay kit (Tosoh 
Corp., Shunan, Japan), because the cross-reactivity of the insulin monoclonal antibody with insulin aspart is reported to be approximately $100 \%{ }^{21}$ In addition, endogenous insulin concentrations were assayed using another enzyme immunoassay kit (LUMIPULSE Presto Insulin; Fujirebio Inc., Tokyo) because we found that the reagent does not cross-react with insulin aspart (Supplemental Fig. 1). The circulating insulin aspart concentration was calculated by subtracting the endogenous insulin concentration from the total insulin concentration. Plasma glucagon and serum RLP-C concentrations were determined using a Daiichi II radioimmunoassay kit (TFB Inc., Tokyo) and a JIMRO II assay kit (Otsuka Pharmaceutical Co., Tokyo), respectively. The other variables were measured by standard methods. The inter-assay coefficients of variation were all $\leq 15 \%$. Haemoglobin $\mathrm{A}_{1 \mathrm{c}}$ (National Glycohemoglobin Standardization Program) values were estimated using the following formula: ${ }^{22}$

Haemoglobin $A_{1 c}$ (National Glycohemoglobin Standardization Program) (\%) $=$ haemoglobin $\mathrm{A}_{1 \mathrm{c}}(\mathrm{Japan}$ Diabetes Society $)(\%)+0.4 \%$

\section{Data analysis}

Metabolic parameter profiles during meal tolerance tests were characterised by recording the values for maximum concentration $\left(C_{\max }\right), t_{\max }$, and the area under the concentration-time curve between 0 and 180 min after meal loading $\left(\mathrm{AUC}_{0-180}\right) . C_{\max }$ and $t_{\max }$ were determined directly from the observed data. $\mathrm{AUC}_{0-180}$ was calculated according to the trapezoidal rule.

Raw or log-transformed data were analysed using a Student's $t$-test or by an 
analysis of variance (ANOVA) or Kruskal-Wallis test followed by Bonferroni post-hoc tests. Associations between variables were assessed using Spearman's rank correlation coefficient. The values are presented as means \pm standard deviation (SD) unless otherwise indicated. Two-sided $P$ values of $<0.05$ were considered statistically significant. All calculations were performed using SPSS for Windows version 11 (SPSS Japan, Tokyo). Graphic representations and curve fitting were performed using Microsoft Excel version 2003. 


\section{RESULTS}

In non-diabetic healthy subjects, the concentration of endogenous insulin rapidly and transiently increased after ingestion of the test meal, with a mean $t_{\max }$ value of 36 min (Fig. 1 and Table 2). The $t_{\max }$ value for endogenous insulin was significantly higher in patients with type 2 diabetes (mean, $84 \mathrm{~min}$; Table 2), and the serum insulin concentration at 180 min after meal loading was higher in diabetic patients than in control subjects $(121 \pm 87$ vs. $39 \pm 18 \mathrm{pmol} / \mathrm{L} ; P<0.05$; Fig. 1$)$. Thus, diabetic patients exhibited delayed mild hyperinsulinaemia after meal loading.

The serum concentration of insulin aspart increased after subcutaneous administration of a therapeutic dose $(0.11 \pm 0.04 \mathrm{U} / \mathrm{kg})$, with a mean $t_{\max }$ of $63 \mathrm{~min}$. The values of $C_{\max }$ and $\mathrm{AUC}_{0-180}$ for insulin aspart were $391 \pm 282 \mathrm{pmol} / \mathrm{L}$ and $42.8 \pm 31.9$ $\mathrm{nmol} \cdot \mathrm{min} / \mathrm{L}$, respectively. Consequently, the $t_{\max }$ for total insulin decreased slightly, and total insulin concentrations $\left(C_{\max }\right.$ and $\left.\mathrm{AUC}_{0-180}\right)$ in the trial involving insulin aspart were twice as high as those in the trial not involving insulin aspart (Table 2). Moreover, insulin aspart administration reduced the $\mathrm{AUC}_{0-180}$ for endogenous insulin by $29 \%$ $(P<0.01)$

As expected, the dose (per body weight) of insulin aspart was significantly correlated with both $C_{\max }$ (Fig. 2a) and $\mathrm{AUC}_{0-180}$ (Fig. 2b). However, the dosage did not affect the $t_{\max }$ for insulin aspart (Fig. 2c). In contrast, the $t_{\max }$ for insulin lispro has been reported to increase dose-dependently. ${ }^{19}$ In addition, body mass index did not correlate with the $t_{\max }$ for insulin aspart (Fig. 2d). These results suggest that the $t_{\max }$ for insulin aspart in clinical practice is more greatly affected by factors other than dosage or level 
of obesity.

The total insulin concentration at 180 min after meal loading tended to remain higher in the trial involving insulin aspart than in the one not involving insulin aspart $(170 \pm 128$ vs. $121 \pm 87 \mathrm{pmol} / \mathrm{L} ; P=0.11)$. Moreover, the $t_{\max }$ for insulin aspart was significantly correlated with the total insulin concentration at $180 \mathrm{~min}$ (Fig. 2e). Collectively, these results indicate that the clinical use of insulin aspart exacerbates delayed hyperinsulinaemia in a subset of patients with type 2 diabetes, notably those with higher $t_{\max }$ values.

Concentration-time profiles for circulating glucose, glucagon, triglycerides, and RLP-cholesterol after ingestion of the test meal are shown in Fig. 3. As shown in Table 2, the administration of insulin aspart significantly attenuated postprandial hyperglycaemia $\left(C_{\max }\right.$ and $\mathrm{AUC}_{0-180}$ for glucose $)(P<0.01)$. The plasma glucose level at 180 min after meal loading was lower than that before meal loading $(6.1 \pm 1.7 \mathrm{vs}$. $7.7 \pm 1.0 \mathrm{mmol} / \mathrm{L} ; P<0.01)$. Although the plasma glucose level fell to less than 3.9 $\mathrm{mmol} / \mathrm{L}$ in two patients, symptoms of hypoglycaemia were not observed in any patient. In addition, insulin aspart significantly increased the $t_{\max }$ for glucagon (Table 2). Compared with the respective values in healthy subjects, postprandial concentrations of triglycerides and RLP-cholesterol $\left(C_{\max }\right.$ and $\left.\mathrm{AUC}_{0-180}\right)$ were significantly higher and tended to be higher, respectively, in diabetic patients (Table 2). However, the abnormal postprandial increases in lipid levels were not statistically significant in the trial involving insulin aspart. 


\section{DISCUSSION}

Previous studies have demonstrated that insulin aspart has a faster onset and shorter duration of action than regular human insulin. ${ }^{7-14}$ In healthy subjects, the mean $t_{\max }$ for insulin aspart has been reported to be $31-33 \mathrm{~min}$ (at a dose of $0.025 \mathrm{U} / \mathrm{kg}$ ), ${ }^{10,18}$ $39 \mathrm{~min}(0.05 \mathrm{U} / \mathrm{kg}),{ }^{10} 52 \mathrm{~min}(0.1 \mathrm{U} / \mathrm{kg}),{ }^{9}$ and $52-70 \mathrm{~min}(0.2 \mathrm{U} / \mathrm{kg}),{ }^{7,8}$ suggesting that the $t_{\max }$ for insulin aspart increases in a dose-dependent manner. In the present study, however, a dose-dependent increase in $t_{\max }$ was not observed for doses of insulin aspart in the range 0.05 to $0.22 \mathrm{U} / \mathrm{kg}$ (Fig. 2c). The value of $t_{\max }$ differed widely between individuals and was 120 min or higher in $20 \%$ of patients (4 of 20). It is known that increasing adiposity (i.e., obesity) delays insulin absorption. ${ }^{23}$ In addition, the absorption and hypoglycaemic action of insulin analogues were reported to be delayed in obese patients with type 2 diabetes. ${ }^{19}$ However, no correlation between $t_{\max }$ for insulin aspart and body mass index was observed in this study (Fig. 2d). Because body mass index does not accurately reflect body fat percentage or subcutaneous fat thickness, it remains to be determined whether or not these factors are associated with $t_{\max }$ for insulin aspart. Regardless, this study demonstrated for the first time that inter-individual differences in the absorption of insulin aspart exist in patients with type 2 diabetes under clinical conditions, irrespective of differences in insulin dosage and body mass index.

Multiple factors, including injection site, skin temperature, physical activity, smoking, and age, can affect the absorption of exogenous insulin. ${ }^{7,24,25}$ Injection depth, which depends on the injection technique, also affects insulin absorption. ${ }^{26}$ Additionally, 
repeated injection of exogenous insulin or one of its analogues (including insulin aspart) at the same site may induce lipoatrophy, resulting in erratic absorption. ${ }^{27}$ In the present study, all patients self-injected insulin aspart into their customary abdominal region using their own devices. In addition, lifestyle habits such as morning exercise and smoking were not restricted. Therefore, various factors may have influenced the value of $t_{\max }$ for insulin aspart. On the other hand, these factors appear to have had minimal effects on the values of $C_{\max }$ and $\mathrm{AUC}_{0-180}$, which were clearly dependent on the dosage of insulin aspart (Figs $2 \mathrm{a}$ and $2 \mathrm{~b}$ ). Interestingly, the reported $t_{\max }$ for insulin aspart at a dose of $0.15 \mathrm{U} / \mathrm{kg}$ differed between patients with type 1 diabetes $(40 \mathrm{~min})^{12}$ and those with type 2 diabetes $(70 \mathrm{~min}),{ }^{14}$ whereas the values of both $C_{\max }(493$ and $507 \mathrm{pmol} / \mathrm{L}$, respectively) and AUC (71.0 and $73.7 \mathrm{nmol} \cdot \mathrm{min} / \mathrm{L}$, respectively) were comparable between the two patient groups. These observations indicate that factors contributing to variation in the value of $t_{\max }$ for insulin aspart need to be identified. However, because multiple factors, rather than a single factor, generally affect insulin absorption in a patient, ${ }^{24}$ and because these factors may influence each other, ${ }^{24}$ it might be difficult to identify the most important factor. Therefore, at least at present, it is important to remember that the value of $t_{\max }$ for insulin aspart differs between individuals and that delayed hyperinsulinaemia is pronounced in some patients.

Delayed hyperinsulinaemia after meals, with and without resulting hypoglycaemia, is likely to increase hunger and hence increase food intake. ${ }^{28,29}$ Moreover, it may stimulate the secretion of counter-regulatory hormones to restore euglycaemia. ${ }^{28}$ As a consequence, delayed hyperinsulinaemia may result in weight gain and worsen 
glycaemic control. In the present study, treatment with insulin aspart exacerbated delayed hyperinsulinaemia, especially in patients with $t_{\max }$ values $\geq 120 \mathrm{~min}$. Therefore, it is possible that these patients are susceptible to the adverse effects of insulin aspart.

Our results demonstrate that treatment with insulin aspart affects not only glucose concentrations but also glucagon concentrations in the postprandial state. Postprandial hyperglucagonaemia and the consequent decreased suppression of hepatic glucose output are thought to contribute to postprandial hyperglycaemia. ${ }^{30,31}$ Specifically, suppression of plasma glucagon concentrations after glucose ingestion is weak in subjects with impaired glucose tolerance ${ }^{31}$ and type 2 diabetes ${ }^{32}$ as compared with normal subjects. In the present study, the loading of a test meal, which contains glucagon secretion-stimulating amino acids, ${ }^{33}$ appeared to increase glucagon concentrations, even in non-diabetic subjects (Fig. 3b). Although postprandial hyperglucagonaemia may be attributable to the reduced action of insulin on pancreatic $\alpha$ cells, ${ }^{30,33}$ insulin aspart significantly affected the value of only $t_{\max }$, and not the values of $C_{\max }$ and $\mathrm{AUC}_{0-180}$ for glucagon in the present study. Therefore, whether the effect of insulin aspart on glucagon secretion contributes to its hypoglycaemic action remains unclear and needs to be determined in future studies.

Similar to postprandial hyperglycaemia, postprandial hyperlipidaemia is a potential risk factor for the development of cardiovascular disease. ${ }^{34}$ Notably, cholesterol-rich remnant-like lipoproteins, whose levels are increased in hypertriglyceridaemia, are thought to be atherogenic factors. ${ }^{34}$ It has been demonstrated that both insulin aspart ${ }^{35}$ and insulin lispro ${ }^{36}$ have more favourable effects than human insulin on postprandial 
hypertriglyceridaemia. Our results confirm the beneficial effect of insulin aspart on postprandial hypertriglyceridaemia and further show its impact on postprandial RLP-cholesterol accumulation.

In summary, the rapid action and favourable pharmacodynamic properties of insulin aspart were preserved in patients with type 2 diabetes, even under clinical conditions. However, the $t_{\max }$ for this insulin analogue differed greatly among individuals. Moreover, delayed hyperinsulinaemia was exacerbated, particularly in patients with higher $t_{\max }$ values. Therefore, to improve the efficacy and safety of insulin aspart in the treatment of patients with type 2 diabetes, the factors responsible for inter-individual variation in the absorption lag time need to be identified. 


\section{ACKNOWLEDGEMENTS}

We are grateful to M. Nagano, M. Nagata, and T. Yoshida for their technical assistance, and to Y. Nakamoto, Y. Matsushima, and Y. Yokoi for their support. We also thank all the participants in this study for their cooperation.

No specific funding was received for this study. 


\section{REFERENCES}

1. Pratley RE, Weyer C. The role of impaired early insulin secretion in the pathogenesis of Type II diabetes mellitus. Diabetologia 2001;44:929-45.

2. Weyer C, Bogardus C, Mott DM, Pratley RE. The natural history of insulin secretory dysfunction and insulin resistance in the pathogenesis of type 2 diabetes mellitus. $J$. Clin. Invest. 1999;104:787-94.

3. Bonora E, Corrao G, Bagnardi V, et al. Prevalence and correlates of post-prandial hyperglycaemia in a large sample of patients with type 2 diabetes mellitus. Diabetologia 2006;49:846-54.

4. DECODE Study Group. Glucose tolerance and cardiovascular mortality: comparison of fasting and 2-hour diagnostic criteria. Arch. Intern. Med. 2001;161:397-405.

5. Sorkin JD, Muller DC, Fleg JL, Andres R. The relation of fasting and 2-h postchallenge plasma glucose concentrations to mortality: data from the Baltimore Longitudinal Study of Aging with a critical review of the literature. Diabetes Care 2005;28:2626-32.

6. Takamura T, Sakurai M, Nakamura M, et al. Factors associated with improvement of fasting plasma glucose level by mealtime dosing of a rapid-acting insulin analog in type 2 diabetes. Diabetes Res. Clin. Pract. 2007;75:278-84.

7. Mudaliar SR, Lindberg FA, Joyce M, et al. Insulin aspart (B28 asp-insulin): a fast-acting analog of human insulin: absorption kinetics and action profile compared with regular human insulin in healthy nondiabetic subjects. Diabetes Care 1999;22:1501-6. 
8. Heinemann L, Weyer C, Rauhaus M, Heinrichs S, Heise T. Variability of the metabolic effect of soluble insulin and the rapid-acting insulin analog insulin aspart. Diabetes Care 1998;21:1910-4.

9. Home PD, Barriocanal L, Lindholm A. Comparative pharmacokinetics and pharmacodynamics of the novel rapid-acting insulin analogue, insulin aspart, in healthy volunteers. Eur. J. Clin. Pharmacol. 1999;55:199-203.

10. Kaku K, Matsuda M, Urae A, Irie S. Pharmacokinetics and pharmacodynamics of insulin aspart, a rapid-acting analog of human insulin, in healthy Japanese volunteers. Diabetes Res. Clin. Pract. 2000;49:119-26.

11. Krones R, Schutte C, Heise T. The rapid-acting properties of insulin aspart are preserved in elderly people with type 2 diabetes. Diabetes Obes. Metab. 2009;11:41-4.

12. Lindholm A, McEwen J, Riis AP. Improved postprandial glycemic control with insulin aspart. A randomized double-blind cross-over trial in type 1 diabetes. Diabetes Care 1999;22:801-5.

13. Osterberg $\mathrm{O}$, Erichsen L, Ingwersen $\mathrm{SH}$, Plum A, Poulsen HE, Vicini P. Pharmacokinetic and pharmacodynamic properties of insulin aspart and human insulin. J Pharmacokinet. Pharmacodyn. 2003;30:221-35.

14. Perriello G, Pampanelli S, Porcellati F, et al. Insulin aspart improves meal time glycaemic control in patients with Type 2 diabetes: a randomized, stratified, double-blind and cross-over trial. Diabet. Med. 2005;22:606-11.

15. Bolli GB, Luzio S, Marzotti $\mathrm{S}$, et al. Comparative pharmacodynamic and pharmacokinetic characteristics of subcutaneous insulin glulisine and insulin aspart 
prior to a standard meal in obese subjects with type 2 diabetes. Diabetes Obes. Metab. 2011;13:251-7.

16. Homko C, Deluzio A, Jimenez C, Kolaczynski JW, Boden G. Comparison of insulin aspart and lispro: pharmacokinetic and metabolic effects. Diabetes Care 2003;26:2027-31.

17. Plank J, Wutte A, Brunner G, et al. A direct comparison of insulin aspart and insulin lispro in patients with type 1 diabetes. Diabetes Care 2002;25:2053-7.

18. von Mach MA, Brinkmann C, Hansen T, Weilemann LS, Beyer J. Differences in pharmacokinetics and pharmacodynamics of insulin lispro and aspart in healthy volunteers. Exp. Clin. Endocrinol. Diabetes 2002;110:416-9.

19. Gagnon-Auger M, du Souich P, Baillargeon JP, et al. Dose-dependent delay of the hypoglycemic effect of short-acting insulin analogs in obese subjects with type 2 diabetes: a pharmacokinetic and pharmacodynamic study. Diabetes Care 2010;33:2502-7.

20. Shimabukuro M, Higa N, Chinen I, Yamakawa K, Takasu N. Effects of a single administration of acarbose on postprandial glucose excursion and endothelial dysfunction in type 2 diabetic patients: a randomized crossover study. J. Clin. Endocrinol. Metab. 2006;91:837-42.

21. Moriyama M, Hayashi N, Ohyabu C, Mukai M, Kawano S, Kumagai S. Performance evaluation and cross-reactivity from insulin analogs with the ARCHITECT insulin assay. Clin. Chem. 2006;52:1423-6.

22. Seino Y, Nanjo K, Tajima N, et al. Report of the Committee on the classification and 
diagnostic criteria of diabetes mellitus. Diabetol. Int. 2010;1:2-20.

23. Vora JP, Burch A, Peters JR, Owens DR. Relationship between absorption of radiolabeled soluble insulin, subcutaneous blood flow, and anthropometry. Diabetes Care 1992;15:1484-93.

24. Heinemann L. Variability of insulin absorption and insulin action. Diabetes Technol. Ther. 2002;4:673-82.

25. Sindelka G, Heinemann L, Berger M, Frenck W, Chantelau E. Effect of insulin concentration, subcutaneous fat thickness and skin temperature on subcutaneous insulin absorption in healthy subjects. Diabetologia 1994;37:377-80.

26. Hofman PL, Derraik JG, Pinto TE, et al. Defining the ideal injection techniques when using 5-mm needles in children and adults. Diabetes Care 2010;33:1940-4.

27. Holstein A, Stege H, Kovacs P. Lipoatrophy associated with the use of insulin analogues: a new case associated with the use of insulin glargine and review of the literature. Expert Opin. Drug Saf. 2010;9:225-31.

28. Ludwig DS. The glycemic index: physiological mechanisms relating to obesity, diabetes, and cardiovascular disease. JAMA 2002;287:2414-23.

29. Rodin J, Wack J, Ferrannini E, DeFronzo RA. Effect of insulin and glucose on feeding behavior. Metabolism 1985;34:826-31.

30. Meier JJ, Kjems LL, Veldhuis JD, Lefebvre P, Butler PC. Postprandial suppression of glucagon secretion depends on intact pulsatile insulin secretion: further evidence for the intraislet insulin hypothesis. Diabetes 2006;55:1051-6.

31. Mitrakou A, Kelley D, Mokan M, et al. Role of reduced suppression of glucose 
production and diminished early insulin release in impaired glucose tolerance. $N$. Engl. J. Med. 1992;326:22-9.

32. Ohneda A, Watanabe K, Horigome K, Sakai T, Kai Y, Oikawa S. Abnormal response of pancreatic glucagon to glycemic changes in diabetes mellitus. J. Clin. Endocrinol. Metab. 1978;46:504-10.

33. Tsuchiyama N, Takamura $\mathrm{T}$, Ando $\mathrm{H}$, et al. Possible role of alpha-cell insulin resistance in exaggerated glucagon responses to arginine in type 2 diabetes. Diabetes Care 2007;30:2583-7.

34. Stalenhoef AF, de Graaf J. Association of fasting and nonfasting serum triglycerides with cardiovascular disease and the role of remnant-like lipoproteins and small dense LDL. Curr. Opin. Lipidol. 2008;19:355-61.

35. Schmoelzer I, de Campo A, Pressl H, et al. Biphasic insulin aspart compared to biphasic human insulin reduces postprandial hyperlipidemia in patients with Type 2 diabetes. Exp. Clin. Endocrinol. Diabetes 2005;113:176-81.

36. Ceriello A, Del Prato S, Bue-Valleskey J, et al. Premeal insulin lispro plus bedtime NPH or twice-daily NPH in patients with type 2 diabetes: acute postprandial and chronic effects on glycemic control and cardiovascular risk factors. J. Diabetes Complications 2007;21:20-7. 
Table 1 Characteristics of the subjects

\begin{tabular}{lcc} 
& $\begin{array}{c}\text { Non-diabetic subjects } \\
\text { Patients with type } 2 \\
\text { diabetes }\end{array}$ \\
\hline$n$ & 5 & 20 \\
Age (years) & $35 \pm 7$ & $60 \pm 11 * *$ \\
Men & $3(60)$ & $14(70)$ \\
Body mass index $\left(\mathrm{kg} / \mathrm{m}^{2}\right)$ & $20.7 \pm 2.2$ & $24.0 \pm 2.5 *$ \\
Fasting plasma glucose & $5.3 \pm 0.3$ & $7.6 \pm 1.2 * *$ \\
(mmol/l) & $34(29.5)$ & $40(50.2)$ \\
Fasting insulin $(\mathrm{pmol} / \mathrm{l})$ & $5.3 \pm 0.1$ & $6.7 \pm 0.5 * *$ \\
Hemoglobin $\mathrm{A}_{1 \mathrm{c}}(\%)$ & & \\
\hline
\end{tabular}

Data are $n, n(\%)$, means $\pm \mathrm{SD}$, or geometric mean (geometric CV\%).

${ }^{*} P<0.05,{ }^{*} P<0.01$ vs. non-diabetic subjects. 
Table 2 Profiles of the metabolic parameters during the meal tolerance test

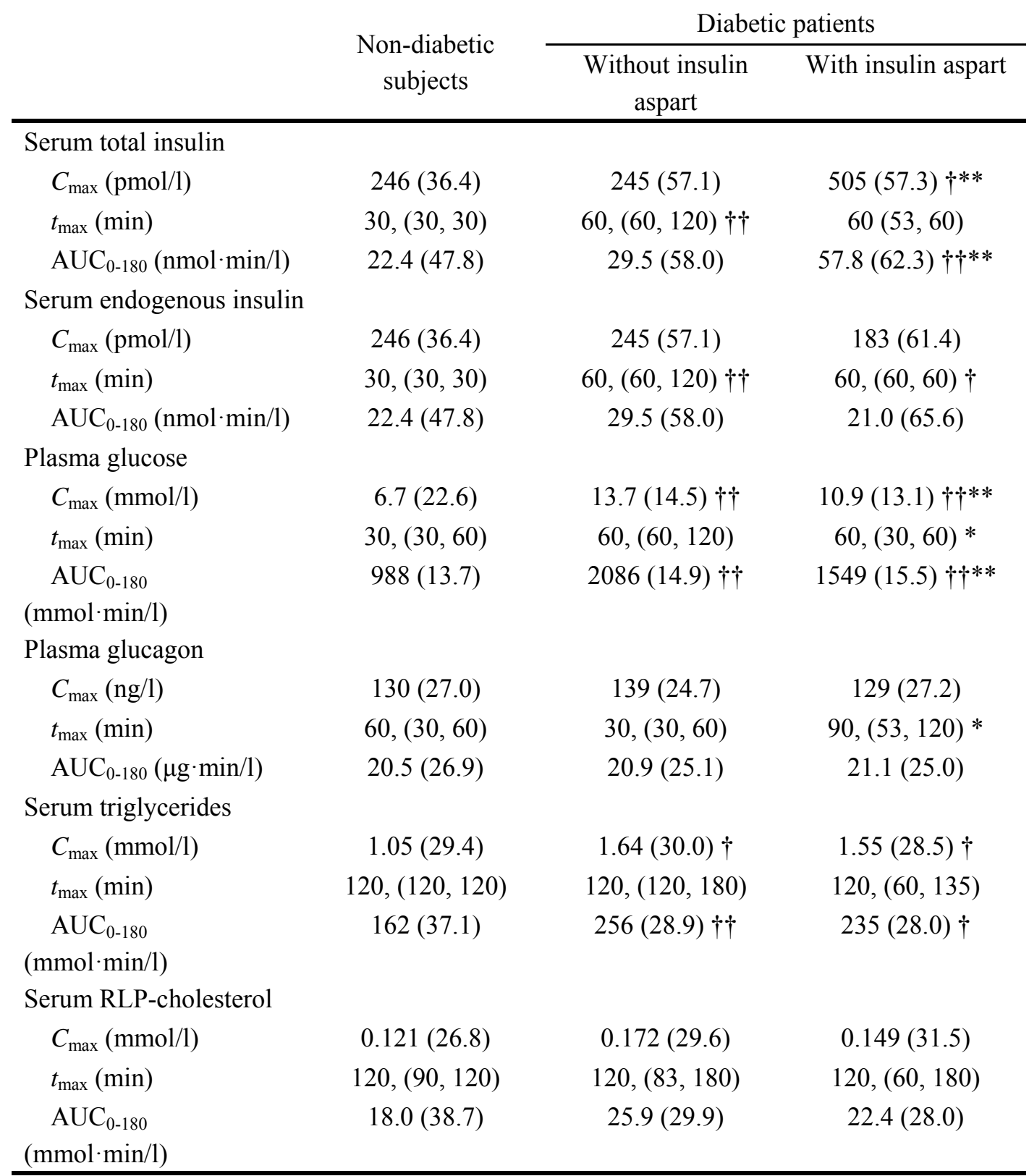

$C_{\max }$, maximum concentration; $t_{\max }$, time to maximum concentration; $\mathrm{AUC}_{0-180}$, area under the concentration-time curve between 0 and $180 \mathrm{~min}$ after meal loading; RLP, remnant-like particle.

Data are geometric mean (geometric $\mathrm{CV} \%$ ) or median (lower and upper quartiles). $\dagger P<0.05, \dagger \dagger P<0.01$ vs. non-diabetic subjects. ${ }^{*} P<0.05,{ }^{* *} P<0.01 \mathrm{vs}$. diabetic patients in the trial without insulin aspart. ANOVA or Kruskal-Wallis test with Bonferroni post-hoc test; three comparisons. 


\section{FIGURE LEGENDS}

\section{Figure 1}

Concentration-time profiles for insulin aspart and endogenous insulin after ingestion of a test meal. After an overnight fast, 20 patients with type 2 diabetes (white circles) and five non-diabetic subjects (white triangles) underwent a meal tolerance test without administration of insulin aspart (dashed lines). The same diabetic patients underwent another test in which insulin aspart was administered subcutaneously just before meal loading (solid lines). The mean dosage of insulin aspart was $7.0 \mathrm{U}$ (range, 3-12 U). Data represent the means \pm SE. White squares, insulin aspart plus endogenous insulin; black squares, insulin aspart; black circles, endogenous insulin. ${ }^{*} P<0.05$ vs. all the other concentration-time profiles (repeated measures ANOVA with Bonferroni post-hoc tests; ten comparisons).

\section{Figure 2}

Relationships between the pharmacokinetic parameters of insulin aspart and drug dose $(\mathbf{a}, \mathbf{b}, \mathbf{c})$, body mass index (d), and total insulin concentration at $180 \mathrm{~min}$ after dosing (e).

\section{Figure 3}

Concentration-time profiles for circulating glucose (a), glucagon (b), triglycerides (c), and RLP-cholesterol (d) after ingestion of a test meal. After an overnight fast, 20 patients with type 2 diabetes (white circles) and five non-diabetic subjects (white 
triangles) underwent a meal tolerance test without administration of insulin aspart (dashed lines). The same diabetic patients underwent another test in which insulin aspart was administered subcutaneously just before meal loading (black circles and solid lines). Data represent the means $\pm \mathrm{SE} .{ }^{*} P<0.05, * * P<0.01$ (repeated measures ANOVA with Bonferroni post-hoc test; three comparisons). 
Trial with insulin aspart (Diabetic patients)

$\rightarrow-$ Insulin aspart + endogenous

$\rightarrow$ Insulin aspart

$\multimap$ Endogenous

Trial without insulin aspart

$-\Delta-$ Non-diabetic patients

- - Diabetic patients

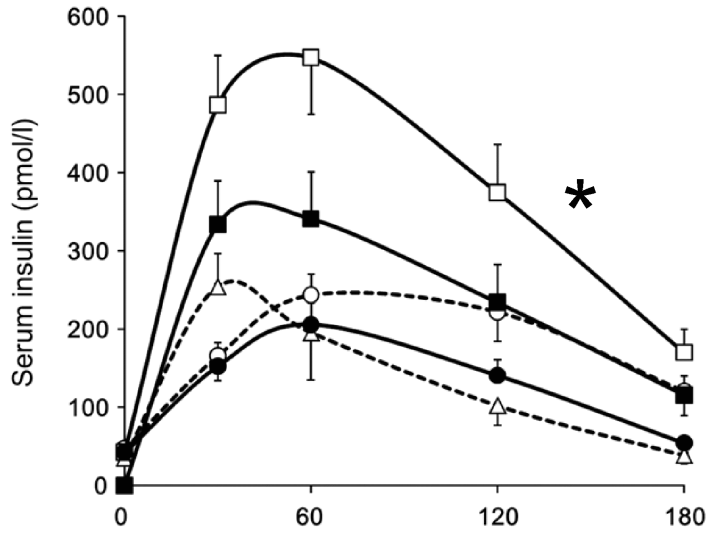

Time (min) 


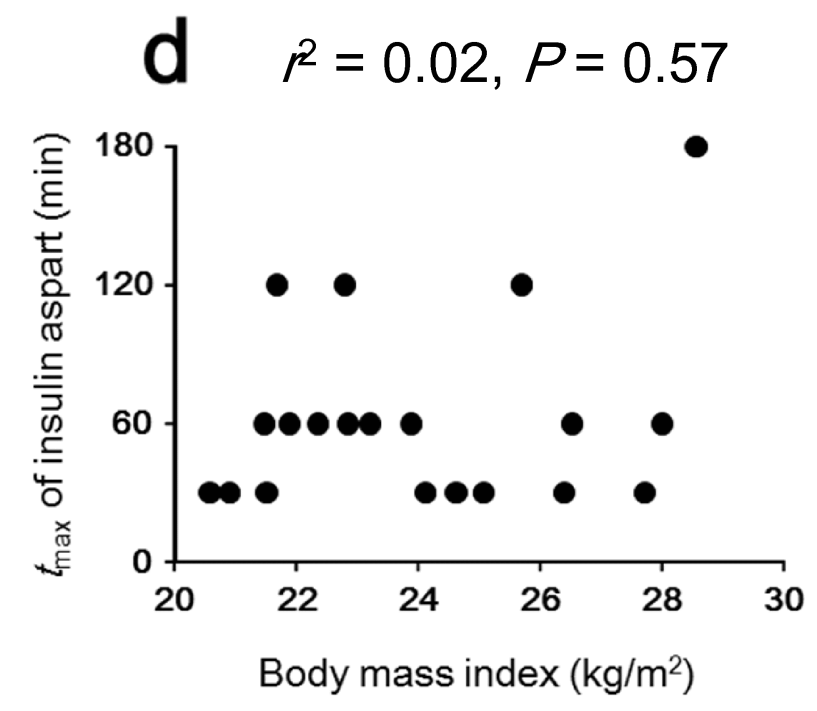

e $r^{2}=0.30, P<0.05$

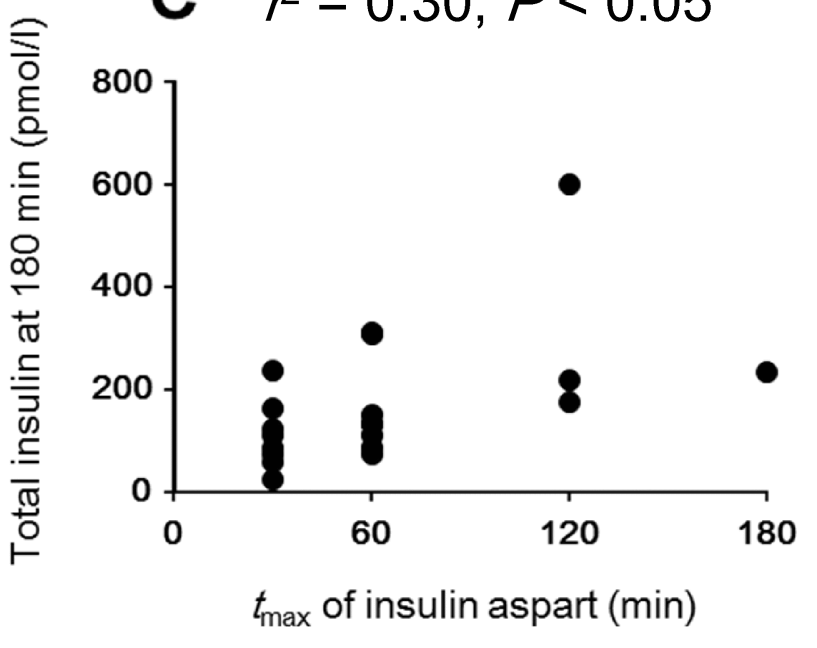




\section{Supplemental Figure}

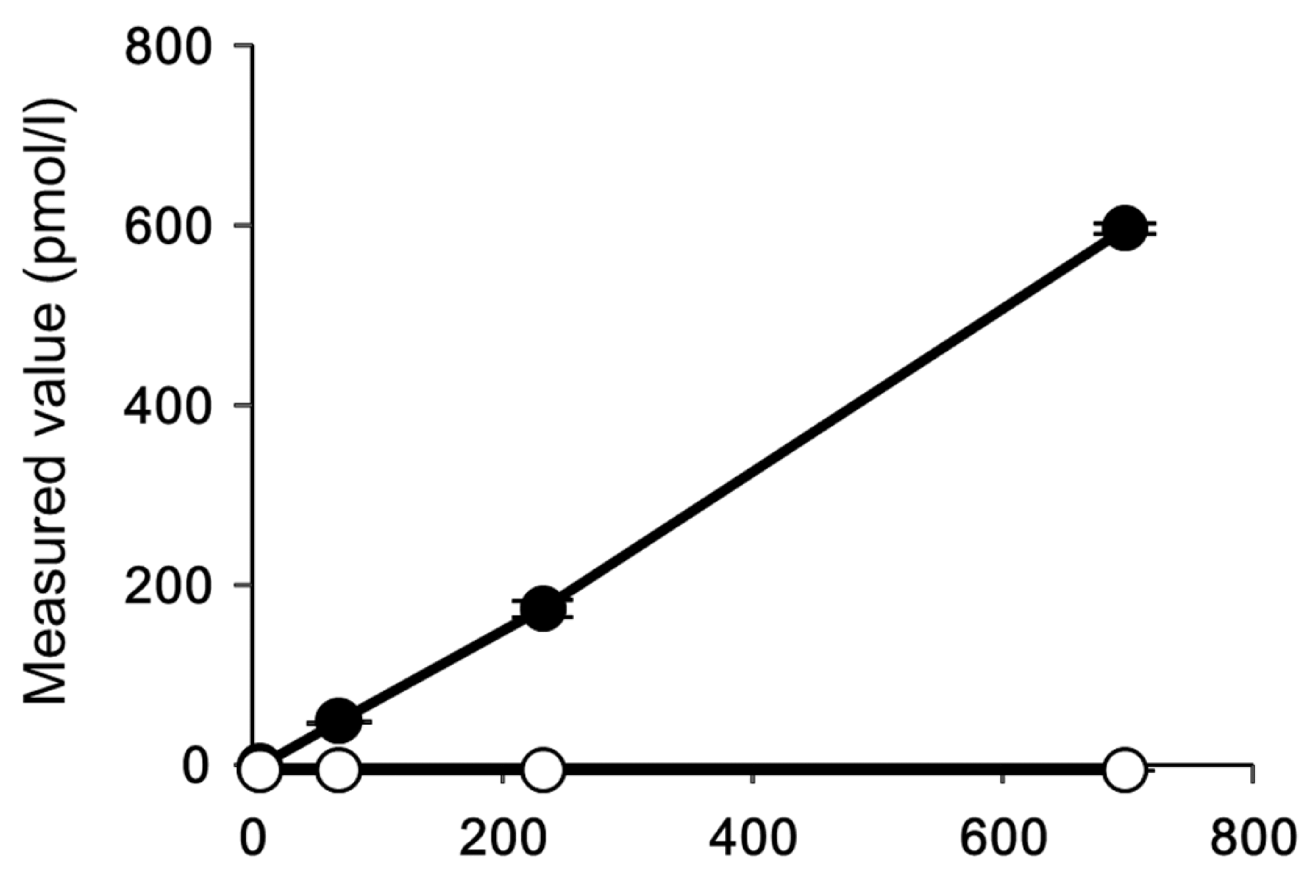

Applied insulin aspart concentration (pmol/l)

In vitro measurements of insulin aspart concentrations.

Concentrations of serial dilutions of insulin aspart in purified water were measured using an E-test TOSOH II IRI kit (black circles) and a LUMIPULSE Presto Insulin kit (white circles). Data represent the means $\pm \mathrm{SD}$ of three measurements. 